\title{
From the Emeritus Founding Editors
}

I T IS A GREAT PRIVILEGE, AND HONOUR, FOR US TO BE given the opportunity to open the final issue of the volume of "Cardiology in the Young" to be published in 2013. This issue marks the start of yet another chapter in the development of our Journal. It is salutary for us to appreciate that it is now almost 25 years since we initiated the publication of a new journal specifically devoted to issues related to the practice of cardiology as seen in the young. Our first issues were put together literally on the kitchen table of one of our homes using nascent desktop publishing software, and printed in the back streets of Kowloon, Hong Kong, using high-resolution four-colour separation processing. It has been a long, but fruitful, road that now sees the journal produced in the printing house of Cambridge University Press.

Our initial efforts could not have been achieved without the support of Lucio Parenzan and the tireless efforts of Giancarlo Crupi, from Bergamo in Italy. The middle part of our development was made possible only with the consistent support and help provided by Geoff Nuttall and his colleagues at Greenwich Medical Publications. It was the acquisition of Greenwich Medical by Cambridge University Press, nonetheless, despite the attendant transitional growing pains, which provided the real impetus to the ongoing development of the Journal. Dan Edwards, Senior Commissioning Editor for journals of Cambridge University Press, deserves special recognition for his own tireless efforts in bridging the many transitional differences, and in keeping the editorial focus on the special opportunities afforded by the inclusion into the family of journals published in Cambridge. Thanks to the efforts of all involved, and in particular the development of a close relationship with the Association for European Paediatric and Congenital Cardiology (AEPC), the journal has continued to make excellent progress under the stewardship of the University Press. The initial part of this particular chapter of the history of our journal took place with ourselves (Fig 1) holding the chief editorial roles. Subsequently, at the time of

Correspondence to: R. H. Anderson, 60 Earlsfield Road, London SW18 3DN, United Kingdom; E-mail: sejjran@ucl.ac.uk one of our retirements, the chief editorial role passed on to Edward Baker.

Ted immediately saw the need to expand the editorial team, and has now been ably supported during his own tenure by Allen Everett and Jeff Jacobs. Together, they have ensured that the journal has maintained the high standards that we had expected, and demanded, from the outset of its publication. Ted has now decided to hand on the editorial baton. We were delighted to learn that it is Jeff Jacobs who will now take over the role of Editorin-Chief. Jeff, nonetheless, will maintain his close association with Allen Everett, who will become Senior Associate Editor. Jeff will bring in Hal Walters as Associate Editor for Surgery. Jeff will also bring in Rodney Franklin as Associate Editor for Cardiology. Rodney and Allen will have the responsibility for those topics primarily paediatric and cardiac. Jeff has then also recruited John Costello to join the team as Associate Editor for Critical Care. Put together, these selections create an immensely strong team, which we are sure will maintain "Cardiology in the Young" as the leading journal in the field of paediatric cardiology and its ancillary disciplines.

All of these individuals are well known to us, and we are gratified that such a strong team has agreed

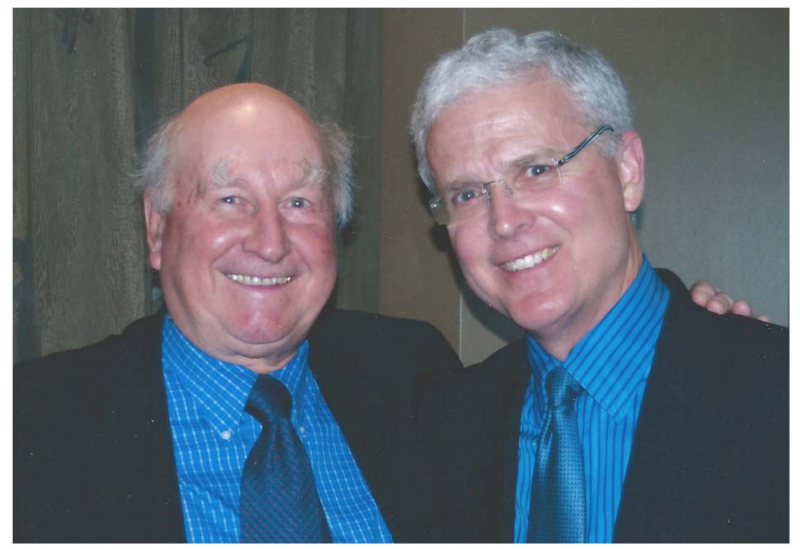

Figure 1.

The Emeritus Founding Editors, taken at an occasion recognising the handing-over of the Editorial chair to Edward Baker. 


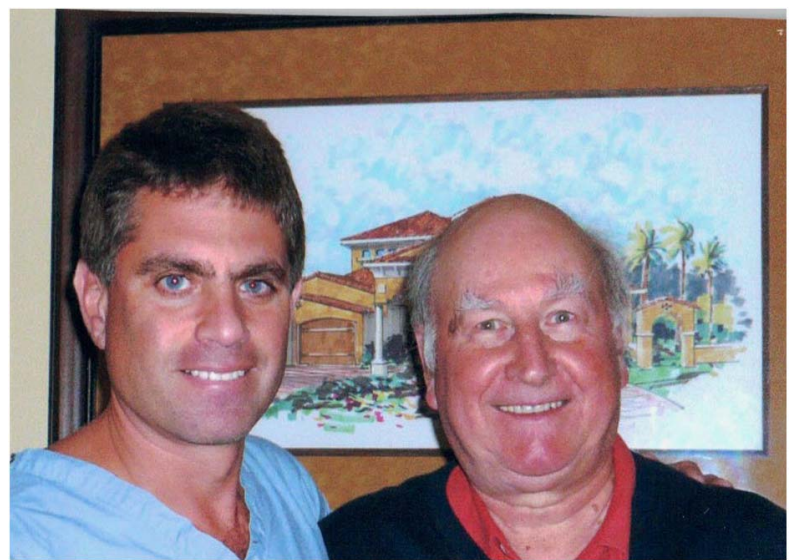

Figure 2.

The new Editor-in-Chief pictured with a previous Editor-in-Chief, taken during one of the excellent symposiums beld in St Petersburg, Florida, and organised in exemplary fashion by the new incumbent.

to work together under the leadership of Jeff. It is the more gratifying for us to see Jeff ascend to the role of Editor-in-Chief. One of us first met Jeff in 1995, when Jeff was a senior registrar at Great Ormond Street. We resumed our discussions during a meeting of the European Association of Cardiothoracic Surgery, held in Glasgow in 1999. In the light of these exchanges, it was a real pleasure to be invited to participate on an annual basis starting in 2002 in the International symposiums organised at St Petersburg in Florida (Fig 2). These events have permitted one of us directly, and the other vicariously, to observe and admire the progression and evolution of Jeff as an instigator and facilitator for all issues relating to publications in paediatric cardiology and paediatric cardiac surgery. He has been a constant supporter of "Cardiology in the Young", as is witnessed by the excellent supplements published to hallmark the activities of the international symposiums held in Florida and elsewhere, combining in this regard with accounts of the content of the meetings organised by Children's Hospital of Philadelphia. Throughout this period, we have also seen Jeff gain in strength in his editorial role. We have been particularly envious of his ability to persuade his colleagues to produce manuscripts in timely and productive fashion, and to obtain sponsorship to permit appropriate publication. All of these attributes bode well for the future of "Cardiology in the Young".

The newly constructed editorial team, therefore, is remarkably well placed to lead the journal into its next chapter. Those publishing in the field of paediatric cardiology will be well aware of the difficulties and problems in obtaining successful submission to high-impact journals such as "Circulation" or "Journal of the American College of Cardiology". It remains a fact that topics relating to paediatric cardiology, or paediatric cardiac surgery, remain very much as "niche" activities in the eyes of those reviewing for these prestigious titles. Journals such as our own, therefore, retain a vital role in bringing recent advances to the attention of those practising specifically in our specialised fields. We have already referred to the crucial interaction with the Association for European Paediatric Cardiology in the evolution of the Journal. We are sure that this association will continue unabated. The new editorial team, nonetheless, has an unmistakable New World bias. This is entirely appropriate. There is no question but that North America, with its vast resources, should be the epicentre of research, teaching, and development in our chosen fields. It has always been a mystery to us why there is no specific society in North America to rival the Association for European Paediatric Cardiology. There is now much more cohesion among the ranks of the North American specialists, although still within the umbrellas of the existing societies. It is our hope that the Journal will continue to foster these activities, offering the opportunities for dissemination of the activities continuing to emerge from the numerous centres of unequivocal excellence existing throughout the New World, and retaining the links with comparable centres in the Old World. At the same time, those practising in these fields need to be kept abreast of the equally important achievements of not only the recent past, but also the history of our young specialities. It is in these areas that we hope to retain our own places in contributing to the ongoing development of the Journal. We recognise the need to increase its impact factor. This can be achieved in no mean fashion by timely publication of authoritative reviews, but hopefully in a Journal that continues to be available in print format. While recognising the economic need for online publication, this cannot detract from the ability to gain knowledge from the printed word, particularly when considering review material. We are delighted to close this editorial, therefore, by announcing that we are pleased to accept the offer to join the new Editorial team as Emeritus Founding Editors with the responsibility for commissioning and production of reviews. In this way, we hope to see the Journal continue to develop in the exponential fashion it has grown during its initial quarter century. We are sure that, in Jeff Jacobs, the Press has chosen the correct person to ensure this continued growth.

\section{Robert H. Anderson, G. William Henry Emeritus Founding Editors Cardiology in the Young}

